\title{
Diagnosis of Pulmonary Hydatid Cyst with
Point of Care Ultrasound in an Emergency Department: A Case Report
}

\section{Acil Serviste Point of Care Ultrasound ile Pulmoner Kist Kidatik Tanısı: Olgu Sunumu}

Nalan Kozaci', Mustafa Avci²

\section{Abstract}

Ultrasonography is widely used for diagnostic and invasive purposes in emergency departments. We present here a case with acquired immune deficiency syndrome who was diagnosed with a hydatid cyst and pneumonia in the lung parenchyma during a pointof-care-ultrasonography examination.

Key words: AIDS, cyst hydatid disease, lung, point of care ultrasonography, POCUS.

\section{Özet}

Ultrasonografi acil servislerde tanısal ve invazif amaçlar için yaygın olarak kullanılmaktadır. Bu yazıda, point-of-care-ultrasonography incelemesi ile akciğer parankiminde kist hidatik ve pnömoni tanısı konulan edinilmiş immün yetersizlik sendromlu bir olguyu sunuyoruz.

Anahtar Sözcükler: AIDS, akciğer, kist hidatik hastalığı, point of care ultrasonografi, POCUS.
'Department of Emergency Medicine, Alanya Education and Research Hospital, Alanya Alaaddin Keykubat University, Antalya,

Turkey

${ }^{2}$ Department of Emergency Medicine, Antalya Education and Research Hospital, University of Health Sciences, Antalya, Turkey
'Alanya Alaaddin Keykubat Üniversitesi, Alanya Eğitim ve Arasstırma Hastanesi, Acil Tıp Anabilim Dalı, Antalya ${ }^{2}$ Sağlık Bilimleri Üniversitesi, Antalya Eğitim ve Araştırma Hastanesi, Acil Tıp Anabilim Dalı, Antalya

Submitted (Başvuru tarihi): 10.04.2020 Accepted (Kabul tarihi): 07.05.2020

Correspondence (iletişim): Mustafa Avcl, Department of Emergency Medicine, Alanya Education and Research Hospital, Alanya Alaaddin Keykubat University, Antalya, Turkey

e-mail: emineafsin@yahoo.com 
Cyst hydatid disease (CHD) is one of the parasitic diseases, resulting from an Echinococcus granulosus pathogen infection. It is mostly encountered in areas where sheep and cattle are raised, and particularly in Mediterranean countries, Central Asia, Northern and Eastern Africa, Australia and South America $(1,2)$. The most common organ to be affected in adults is the liver, followed by the lungs. A CHD diagnosis is based on clinical findings, serologic tests and imaging features $(3,4)$.

Conventional X-ray (XR), computed tomography (CT) and magnetic resonance imaging (MRI) of the lungs are the various modalities that can reveal the presence of a thoracic hydatid cyst, although both $C T$ and $X R$ imaging involve potential radiation exposure $(2,4,5)$. MRI is not always accessible in emergency situations. Ultrasonography (US) is the primary imaging modality used to diagnose and evaluate CHD in the liver, although it may be used for diagnoses in any area accessible by the US probe and with a good acoustic window. These extrahepatic locations include the spleen, kidneys, pelvis and heart $(4,5)$.

In the last decade, many clinicians have started to use US for specific purposes, known as "focused US" or "point of care US" (POCUS). Clinicians prefer POCUS for the visualization of many parts of the body in intensive care, the emergency department and pre-hospital settings (6-8) In this report, we present a case with acquired immune deficiency syndrome (AIDS) who was diagnosed with a hydatid cyst and pneumonia in the lung parenchyma upon a POCUS examination. The patient provided written informed consent for their anonymized information to be published in this article.

\section{CASE}

A 35-year-old female patient was admitted to the emergency department with complaints of dyspnea and hemoptysis. The patient reported also fever and cough, and HIV infection. The vital signs of the patient were as follows: fever $37.7^{\circ} \mathrm{C}$; arterial blood pressure $125 / 82 \mathrm{mmHg}$; heart rate 119 beats $/ \mathrm{min}$; respiration rate $28 / \mathrm{min}$; and pulse oximetry $95 \%$ in room air. Upon examination, the patient was found to be in respiratory distress. Lung examination revealed decreased breathing sounds in the left lung. Other physical examination findings were normal. In lab tests, an arterial blood gas analysis revealed no hypoxia, although she had mild compensated respiratory alkalosis. The other laboratory test findings were as follows: C-reactive protein level $256 \mathrm{mg} / \mathrm{L}$ (reference range (RR): 0-9); hemoglobin $11.3 \mathrm{~g} / \mathrm{dl}$ (RR: 12-15); leukocyte count 28.0 (RR: 3.6-10.2x103); and platelet count 608,000/mm3 (RR: 159-388x103). Alanine aminotransferase was $137 \mathrm{U} / \mathrm{L}(\mathrm{RR}<50)$; aspartate aminotransferase was $284 \mathrm{U} / \mathrm{L}(\mathrm{RR}<50)$; gamma glutamyl transferase was $114 \mathrm{U} / \mathrm{L}(\mathrm{RR}<38)$; alkaline and phosphatase was $283 \mathrm{U} / \mathrm{L}$ (RR: 30-120). Kidney function tests were normal; an HIV-specific enzyme-linked immunosorbent assay (ELISA) antibody test was positive; a hydatid cyst (indirect hemagglutination) test was $1 / 1280 \mathrm{~g} / \mathrm{L}$; and parenchymal opacity and siluet sign on the lower surface of the left lung were observed in the posterio-anterior lung XR (Figure 1). A lung examination with POCUS was performed by an emergency physician using $7.5 \mathrm{MHz}$ linear and $3.5 \mathrm{MHz}$ convex transducers with a standard US tool (Mindray DC-T6, Germany). After clinical and POCUS examinations, a CT scan was performed, revealing cyst, pleural effusion and infiltration areas in the left lung (Figure 1). The cyst was a well-circumscribed, fluid density lesion with homogenous content, $90 \mathrm{~mm}$ in diameter, and left lung volume was decreased due to the mass effect of the cyst. Another cyst was observed in the medial part of the spleen.

The patient was admitted to the intensive care unit with a diagnosis of pneumonia and CHD. An operation for the resection of the cyst was recommended by the thoracic surgeon, but the patient declined and discharged herself from hospital on the sixth day of hospitalization.

Ultrasound Technique: Each hemithorax was divided into six areas, with longitudinal lines passing through the midsternal, midclavicular and anterior axilla, and with transverse lines passing through the areola of the breast. Each area was evaluated with linear and convex transducers in the longitudinal and transverse planes. Ultrasound findings, such as artifacts (A line, B line), lung sliding, alveolar consolidation and pleural effusions, were recorded in all areas.

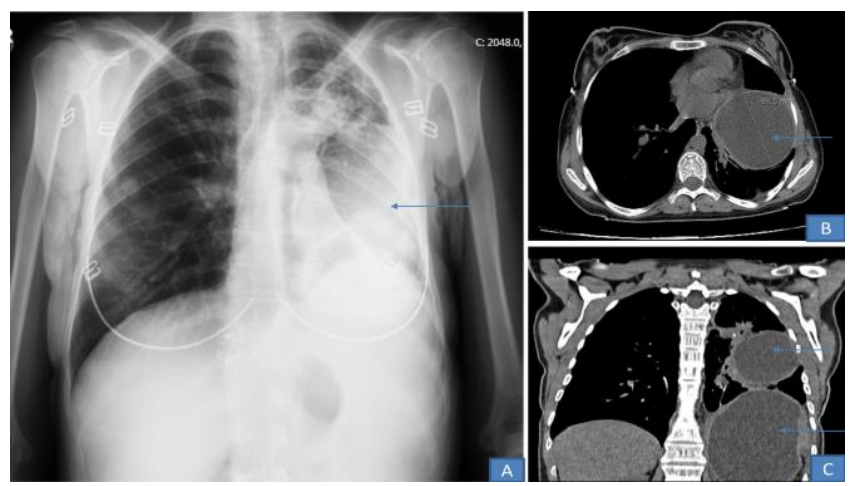

Figure 1: Posterioanterior chest X-ray (A), Thorax Computed Tomography cross-section (B), Thorax computed tomography coronal section (C) 


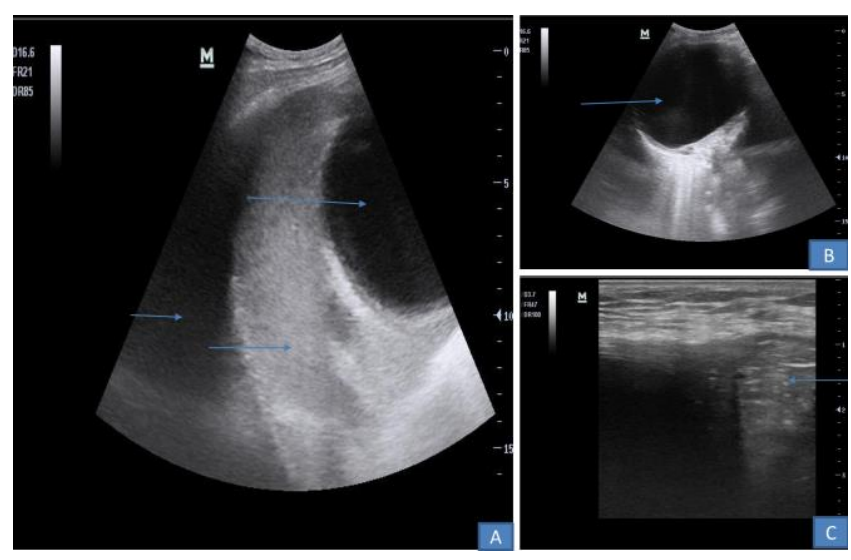

Figure 2: POCUS, abdominal Hydatid Cyst, Spleen and pleural fluid, (A), POCUS, hydatid cyst in the lung parenchyma (B), POCUS, pneumonic infiltration (C)

Ultrasound Findings: Pleural effusion, infiltration areas and cystic structure were revealed in the left upon the POCUS examination. The diameter of the cyst, which was well-circumscribed, unilocular and round, was $76 \times 87 \mathrm{~mm}$, with anechoic and homogeneous content (Figure 2).

The cyst was considered to be a hydatid cyst, and so the emergency physician performed an abdominal examination with US. The liver, gall-bladder, right kidney, pancreas, left kidney, spleen, bladder and uterus were examined sequentially with US and screened for cysts. A cyst was detected in the abdomen adjacent to the spleen measuring $11.12 \times 8.73 \mathrm{~cm}$ in diameter, of a type similar to the lung cyst. The cyst was well-circumscribed, anechoic and had homogenous content (Figure 2).

\section{DISCUSSION}

The lungs are one of the main target organs for HIVrelated diseases, and almost $70 \%$ of patients experience at least one respiratory complication during their illness. The common lung manifestations of HIV/AIDS are opportunistic infections, emphysema and bronchiolitis, lymphoproliferative diseases and AIDS-related malignancies. The broad spectrum of the disease makes differential diagnosis difficult, and so clinical and radiological findings should be evaluated together for accurate diagnosis (9).

Pulmonary CHD may cause chest pain, dry cough and hemoptysis, while large cysts can cause shortness of breath with the effect of the mass. Acute onset symptoms and anaphylactic reactions should suggest cyst rupture. In some cases, CHD may be asymptomatic and detected only incidentally. Pulmonary hydatid cysts may be single or multiple, and single cysts are more common. CHD should be suspected when well-defined homogeneous radiopacity is seen on the chest $\mathrm{X}$-ray. The $\mathrm{CT}$ features of uncomplicated hydatid cysts appear as well-circumscribed fluid attenuation lesions with homogenous content and smooth, hyperdense walls $(2,3)$. CHD treatment can be both medical and surgical, with indications for surgery including large cysts that are superficial and likely to rupture, infected cysts, cysts in vital anatomical locations, and cysts that cause mass effect (2).

Ultrasound (US) has long been used to aid diagnosis and to guide therapy in many tropical infectious diseases. Over past two decades, technological advances have improved image quality and significantly reduced the size and price of US equipment (5). As a result, US has emerged as a preferred point-of-care test in clinical decision-making and for procedural guidance in various medical specialties (3). Bedside POCUS by clinicians is common today $(4,10)$. The fundamental difference between POCUS and a conventional US examination is that POCUS is performed by the treating physician. POCUS aims to answer simple, usually binary questions related to immediate patient management (e.g., "Is there a pleural or pericardial effusion? Yes or no") $(5,10)$, rather than being a comprehensive US assessment (11).

Nowadays, clinicians use US for the diagnosis of such lung diseases as pneumothorax, lung contusion, pulmonary edema and pneumonia. US is also used for the diagnosis of pulmonary abscess, pleural fluid with mass and consolidation (6,11-13). The BLUE protocol is an approach used for the diagnosis of lung diseases in which the physician is directed step-by-step from differential diagnosis to diagnosis in patients with acute dyspnea (11). In a study of HIV-infected patients, the pulmonary US characteristics of five different common lung diseases (bacterial pneumonia, Pneumocystis jirovecii pneumonia, tuberculosis, cytomegalovirus pneumonia and nonHodgkin's lymphoma) were investigated. Characteristic US patterns have been observed in Pneumocystis jirovecii pneumonia and pulmonary lymphoma (14).

US is widely used as an imaging modality in the diagnosis of CHD, and a sonographic classification has been developed to standardize the diagnostic and therapeutic steps of CHD (cystic echinococcosis (CE)), in which CE 1 stage refers to a simple round or oval unilocular cyst with anechoic content and a visible double cystic wall; CE2 stage refers to a cyst that is completely filled with daughter vesicles; CE3 is divided into two stages: CE3a and CE3b, the first of which is characterized by a "water lily" sign, represented by floating membranes, while the latter is predominantly a solid lesion with daughter vesicles. Finally, CE4 and CE5 stages refer to involution and solid- 
ification of cyst content with increasing degrees of calcification $(2,3,15)$.

US is not used in routine practice for the diagnosis of pulmonary hydatid cyst. In one study, US findings related to the cystic wall were investigated in the diagnosis of a pulmonary hydatid cyst. In this study, a double-layered wall in univesicular cysts and a double-layered septum in multivesicular cysts were described as the "wall sign" related to pulmonary hydatid cysts (16).

In the present case, symptoms and clinical findings that were suggestive of lung pathology were predominant. Parenchymal opacity and silhovette sign in the left lung were revealed in XR, after which a POCUS examination was performed. The bedside POCUS examination revealed pneumonic infiltration, cyst and pleural effusion in the left lung. The cyst was large and had a mass effect. It was concluded that the pneumonic infiltration and mass effect of the cyst together had caused a decrease in AC capacity. The cyst was thought to be hydatid disease due to being very large simple, anechoic and well-limited, and due to the patients HIV status. Accordingly, the abdominal organs were screened for cysts with POCUS. A cyst of a similar structure to the lung parenchyma was imaged in the spleen, strengthening the preliminary diagnosis of CHD. The cyst in the spleen was classified as CE1. Furthermore, the size and localization of the cysts were determined by POCUS, and the laboratory tests results confirmed the diagnosis of CHD. The treatment decision was made based on the POCUS findings and laboratory tests results. This issue is important for the diagnosis and treatment decision of CHD.

\section{CONCLUSION}

In conclusion, POCUS can be used for differential diagnosis in cases where lung pathology is suspected in the emergency department. US may be used as an alternative to other imaging modalities for the imaging of cystic structures in lung CHD, and for the identification of cyst size and other features.

\section{CONFLICTS OF INTEREST}

None declared.

\section{AUTHOR CONTRIBUTIONS}

Concept - N.K., M.A.; Planning and Design - N.K., M.A.; Supervision - N.K., M.A.; Funding - N.K., M.A.; Materials - N.K., M.A.; Data Collection and/or Processing - N.K., M.A.; Analysis and/or Interpretation - N.K., M.A.; Litera- ture Review - N.K., M.A.; Writing - N.K., M.A.; Critical Review - N.K., M.A.

\section{YAZAR KATKILARI}

Fikir - N.K., M.A.; Tasarım ve Dizayn - N.K., M.A.; Denetleme - N.K., M.A.; Kaynaklar - N.K., M.A.; Malzemeler - N.K., M.A.; Veri Toplama ve/veya İşleme - N.K., M.A.; Analiz ve/veya Yorum - N.K., M.A.; Literatür Taraması - N.K., M.A.; Yazıyı Yazan - N.K., M.A.; Eleştirel inceleme - N.K., M.A.

\section{REFERENCES}

1. Erayman I, Kalkan E, Erdi F, Kerimoglu U, Esen H. Primary Spinal Hydatid Cyst in A Patient With Acquired Immunodeficiency Syndrome. Eur Spine J 2011; 20(Suppl 2): S235-8. [CrossRef]

2. Sarkar M, Pathania R, Jhobta A, Thakur BR, Chopra R. Cystic pulmonary hydatidosis. Lung India. 2016; 33:17991. [CrossRef]

3. Garg MK, Sharma M, Gulati A, Gorsi U, Aggarwal AN, Agarwal $R$, et al. Imaging in pulmonary hydatid cysts. World J Radiol 2016; 8: 581-7. [CrossRef]

4. Zalaquett E, Menias C, Garrido F, Vargas M, Olivares JF, Campos D, et al. Imaging of Hydatid Disease with a Focus on Extrahepatic Involvement. Radiographics 2017; 37:901-23. [CrossRef]

5. Belard S, Tamarozzi F, Bustinduy AL, Wallrauch C, Grobusch MP, Kuhn W, et al. Point-of Care Ultrasound Assessment of Tropical Infectious Diseases A Review of Applications and Perspectives. Am J Trop Med Hyg 2016; 94:8-21. [CrossRef]

6. Kozaci N, Ava M, Ararat E, Pinarbasili T, Ozkaya M, Etli I, et al. Comparison of ultrasonography and computed tomography in the determination of traumatic thoracic injuries. Am J Emerg Med 2019; 37:864-8. [CrossRef]

7. Kozaci N, Avci M, Tulubas G, Ararat E, Karakoyun OF, Karaman C, et al. Role of emergency physicianperformed ultrasound in the differential diagnosis of abdominal pain. Hong Kong J Emerg Med 2020; 27 79-86. [CrossRef]

8. Kozaci N, Ay MO, Akcimen M, Turhan G, Sasmaz I, Turhan $S$, et al. Evaluation of the effectiveness of bedside point-of-care ultrasound in the diagnosis and management of distal radius fractures. Am J Emerg Med 2015 33:67-71. doi: 10.1016/i.ajem.2014.10.022. Epub 2014 Oct 22. [CrossRef]

9. Allen $C M, A L-J a h d a l i ~ H H$, Irion $K L$, Ghanem $S A$, Alaa Gouda A, Khan AN. Imaging lung manifestations of HIV/AIDS. Ann Thorac Med 2010; 5:201 - 16. [CrossRef] 
10. Kameda T, Taniguchi N. Overview of point-of-care abdominal ultrasound in emergency and critical care. J Intensive Care 2016; 4:53. doi:10.1186/s40560-016$0175-y$. [CrossRef]

11. Patel CJ, Bhatt HB, Parikh SN, Jhaveri BN, Puranik JH. Bedside lung ultrasound in emergency protocol as a diagnostic tool in patients of acute respiratory distress presenting to emergency department. J Emerg Trauma Shock 2018; 11: 125-9. [CrossRef]

12. Lichtenstein DA, Mezière GA. Relevance of lung ultrasound in the diagnosis of acute respiratory failure: The BLUE protocol. Chest 2008; 134:117-25. [CrossRef]

13. Heller T, Wallrauch C, Goblirsch S, Brunetti E. Focused assessment with sonography for HIV-associated tubercu- losis (FASH): A short protocol and a pictorial review. Crit Ultrasound J 2012; 4:21. [CrossRef]

14. Heuvelings CC, Bélard S, Janssen S, Wallrauch C, Grobusch MP, Brunetti $E$, et al. Chest ultrasonography in patients with HIV: a case series and review of the literature. Infection 2016; 44:1-10. [CrossRef]

15. Brunetti E, Tamarozzi F, Macpherson C, Filice C, Schindler-Piontek M, Kabaalioglu A, et al. Ultrasound and cystic echinococcosis. Ultrasound Int Open 2018; 4: E70-E78. [CrossRef]

16. El Fortia M, El Gatit A, Bendaoud M. Ultrasound wallsign in pulmonary echinococcosis (New application). Ultraschall Med 2006; 27:553-7. [CrossRef] 